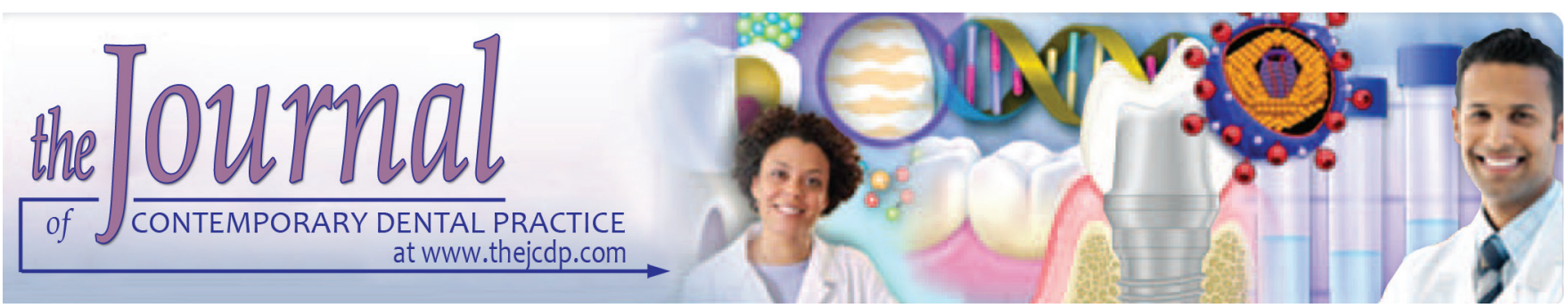

\title{
Diametral Tensile Strength, Flexural Strength, and Surface Microhardness of Bioactive Bulk Fill Restorative
}

\section{Ali Alrahlah}

\begin{abstract}
Aim: The aim was to perform comparative analysis of bioactive, contemporary bulk-fill resin-based composites (RBCs) and conventional glass-ionomer materials for flexural strength (FS), diametral tensile strength (DTS), and Vickers hardness number $(\mathrm{VHN})$ in the presence of thermocycling.
\end{abstract}

Materials and methods: Five restorative materials [Tetric $\mathrm{N}$-Ceram Bulk Fill; smart dentin replacement (SDR) Flowable Material; Bioactive restorative material (ACTIVA Bulk Fill); Ketac Universal Aplicap; and GC Fuji II] were evaluated for DTS, FS, and VHN. Half the samples in each material group were thermocycled. The DTS was performed under compressive load at a cross-head speed of $1.0 \mathrm{~mm} / \mathrm{min}$. The FS was assessed by three-point bending test at a cross-head speed of $0.5 \mathrm{~mm} / \mathrm{min}$. The VHN was determined using a Vickers diamond indenter at $50 \mathrm{gf}$ load for 15 seconds. Differences in FS, DTS, and VHN were analyzed using analysis of variance (ANOVA) and Tukey post hoc tests at $\alpha=0.05$ level of significance.

Results: N-Ceram, ACTIVA, and SDR demonstrated the highest and comparable $(p>0.05)$ FS. The SDR had the highest DTS value $(141.28 \pm 0.94)$, followed by $\mathrm{N}$-Ceram $(136.61 \pm 1.56)$ and ACTIVA $(129.05 \pm 1.78)$. Ketac had the highest VHN value before and after thermocycling.

Conclusion: ACTIVA showed mechanical properties (FS and DTS) comparable with bulk-fill resin composite materials. ACTIVA showed potential for durability, as VHN was comparable post-thermocycling.

Clinical significance: Bioactive materials showed acceptable DTS and FS values. However, hardness was compromised compared with included materials. ACTIVA Bulk Fill shows potential for dentin replacement but it needs to be covered with a surface-resistant restorative material. Further studies to improve surface characteristics of ACTIVA Bulk Fill are recommended.

Department of Restorative Dental Science, King Saud University Riyadh, Kingdom of Saudi Arabia

Corresponding Author: Ali Alrahlah, Department of Restorative Dental Science, King Saud University, Riyadh, Kingdom of Saudi Arabia, Phone: +00966114678304, e-mail: aalrahlah@ ksu.edu.sa
Keywords: Bioactive, Bulk fill, Mechanical properties, Resin composite, Thermocycling.

How to cite this article: Alrahlah A. Diametral Tensile Strength, Flexural Strength, and Surface Microhardness of Bioactive Bulk Fill Restorative. J Contemp Dent Pract 2018;19(1):13-19.

Source of support: Nil

Conflict of interest: None

\section{INTRODUCTION}

The use of RBCs as restorative materials has rapidly increased during the past few decades. Their unique properties including ease of handling and successful clinical performance have made them the material of choice for dental practitioners. ${ }^{1}$ The RBC demonstrates improved esthetics, mechanical properties, and bonding strength to tooth structure. Hence, they are considered compatible materials for direct anterior and posterior restorations. ${ }^{2}$ Their clinical performance and longevity have demonstrated durability; however, the limitations with $\mathrm{RBC}$ restoration still exist. ${ }^{2}$ The physicochemical and mechanical properties of such polymers depend on the degree of conversion (DC) and definitive network structure. ${ }^{3}$ In addition, the type of monomer has a significant influence on the polymerization reaction, mechanical properties, and water sorption of RBCs. ${ }^{4}$ The durability and performance of bulk-fill RBCs can be evaluated by characterization of their mechanical properties. ${ }^{5}$ For instance, material hardness is a measure of degree of polymerization and resistance to surface wear. ${ }^{6}$ Similarly, resistance to fracture and clinical failure of restorative materials reflect flexural and compressive strengths. ${ }^{7}$ Moreover, outcomes of DTS testing were developed to investigate brittle materials with little or no plastic deformation. ${ }^{8}$ All these properties are critical for the clinical survival of resin-based restorations.

Continued development in material sciences has resulted in the introduction of bioactive restorative 
materials. ${ }^{9}$ They elicit a response from teeth, activating a mechanism for the purpose of tissue repair or synthesis by artificial means. ${ }^{10}$ These materials have undergone modifications to improve their mechanical properties critical for clinical function and survival. ${ }^{11,12}$ A similar material, Bioactive bulk-fill, has been introduced with the claim of improved mechanical strength, toughness, and fracture resistance. In comparison with RBC restorative materials, bioactive materials have minimal polymerization shrinkage $(<1.7 \%)$ in addition to their ability to stimulate remineralization. ${ }^{13}$ Moreover, their composition is resinmodified glass-ionomer cement(RMGIC) and they form intimate contact with the dentin walls and display hydrophilicity. ${ }^{14,15}$ All these properties allow dental bioactive materials to minimize gap formation and microleakage at the restoration-tooth interface. Another critical factor in the survival of bioactive restorative materials is their resistance to breakdown in the oral environment during function i.e., mechanical resistance. ${ }^{15}$ However, there is a dearth of studies comparing mechanical properties of contemporary bulk-fill RBCs and bioactive bulk-fill materials.

A comparison of a novel bioactive material's (ACTIVA) mechanical properties with conventional RBCs and glass ionomer cement (GIC) restorative materials will enable practitioners to make informed evidence-based clinical decisions and predict prognosis of restorative materials. In addition, simulation of oral conditions for restorative material testing is often provided by in vitro thermocycling (clinical aging). However, to our knowledge from indexed literature, there are no studies assessing and comparing the mechanical properties of FS, DTS, and microhardness of bioactive (ACTIVA) and conventional restorative materials (RBC and GIC). It is hypothesized that there will be no difference in the mechanical properties of bioactive bulk fill, contemporary bulk-fill RBCs, and conventional bulk-fill GIC-based materials.
Therefore, the aim was to perform a comparative analysis of bioactive, contemporary RBCs, and conventional GIC bulk-fill materials for microhardness VHN, DTS, and FS in the presence of thermocycling.

\section{MATERIALS AND METHODS}

Five direct resin-based restorative materials were evaluated for DTS, FS, and microhardness properties (VHN). The materials included Tetric N-Ceram Bulk Fill (Ivoclar-Vivadent), SDR Flowable Material (DENTSPLY Caulk, Milford, DE, USA), ACTIVA (PULPDENT, Germany), Ketac Universal Aplicap (3M Deutschland GmbH, Germany), and GC Fuji II LC (GC Corporation, Tokyo, Japan). The composition of tested materials is presented in Table 1.

\section{Diametral Tensile Strength}

Totally, 10 cylindrical ( $4.0 \mathrm{~mm}$ diameter $\times 6 \mathrm{~mm}$ height) specimens were fabricated from each material (five groups) according to manufacturer's specifications. The materials were inserted and packed in a customized cylindrical polyvinylsiloxane (PVS) material (Putty, Express ${ }^{\mathrm{TM}}$ STD; 3M ESPE, USA) whose ends were blocked with two glass slides. The material was light-cured using Elipar ${ }^{\mathrm{TM}}$ S10 (3M ESPE, USA) for 20 seconds through each end of the cylinder. The specimens were removed from the mold and the excess material was trimmed using a 600 grit silica-carbide ( $\mathrm{SiC}$ ) paper. Specimens were stored in a lightproof container with distilled water, and later were stored in the incubator (Memmert Edestahl, Rostfrei, West Germany) at $37^{\circ} \mathrm{C}$ and $100 \%$ relative humidity for 24 hours. Five specimens in each material group were thermocycled (Thermocycler SD Mechatronik, GmbH Dental Research Equipment, Germany) for 5,000 cycles at $5^{\circ} \mathrm{C}$ and $55^{\circ} \mathrm{C}$ (dwelling time: cold bath, 30 seconds; hot bath, 30 seconds) and the other half of samples did not

Table 1: Technical characteristics of the tested materials

\begin{tabular}{|c|c|c|}
\hline Materials & Composition details & Filler \\
\hline $\begin{array}{l}\text { Tetric N-Ceram; Ivoclar Vivadent, Schaan, } \\
\text { Liechtenstein }\end{array}$ & $\begin{array}{l}\text { DMA: } 19-21 \% \text { weight, ethyoxylated } \\
\text { bisphenol A DMA, Bis-GMA }(3-<10 \%)\end{array}$ & $\begin{array}{l}\text { Barium glass, ytterbium, trifluoride, and } \\
\text { mixed oxide }\end{array}$ \\
\hline SDR Dentsply Caulk, Milford, DE, USA & $\begin{array}{l}\text { Modified UDMA resin, ethoxylated } \\
\text { bisphenol A DMA, triethylene glycol DMA }\end{array}$ & $\begin{array}{l}\text { Barium-alumino-fluoro-borosilicate glass, } \\
\text { strontium alumino-fluoro-silicate glass } \\
\text { ( } 68 \text { weight } \% / 45 \text { volume } \% \text { ) }\end{array}$ \\
\hline $\begin{array}{l}\text { ACTIVA bioactive, ionic composite resin, } \\
\text { Pulpdent, Germany }\end{array}$ & $\begin{array}{l}\text { Blend of diurethane and other } \\
\text { methacrylates with modified polyacrylic } \\
\text { acid ( } 44.6 \%) \text {, contain no bisphenol A, no } \\
\text { bis-GMA, no BPA derivatives }\end{array}$ & $\begin{array}{l}\text { Amorphous silica }(6.7 \%) \text {, sodium fluoride } \\
(0.75 \%)\end{array}$ \\
\hline $\begin{array}{l}\text { Ketac Universal Aplicap, GIC restorative, } \\
\text { 3M Deutschland GmbH, Germany }\end{array}$ & $\begin{array}{l}\text { Water, copolymer of acrylic acid-maleic } \\
\text { acid, tartaric acid, no BPA derivatives } \\
\text { present }\end{array}$ & Oxide glass \\
\hline $\begin{array}{l}\text { GC Fuji II LC GC Corporation, reinforced } \\
\text { GIC, Japan }\end{array}$ & $\begin{array}{l}\text { Distilled water }(20-30 \%) \text {, polyacrylic } \\
\text { acid }(20-30 \%), 2 \text {-hydroxymethacrylate } \\
(30-35 \%), \text { UDMA }(<1 \%)\end{array}$ & Fluoro-alumino-silicate glass \\
\hline
\end{tabular}




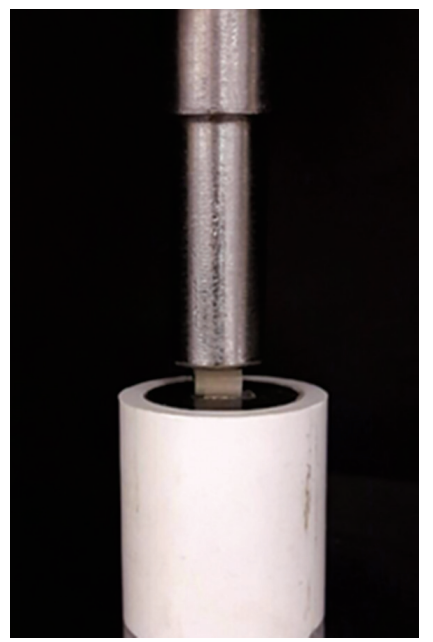

Fig. 1: Diametral tensile strength testing assembly using instron universal testing machine

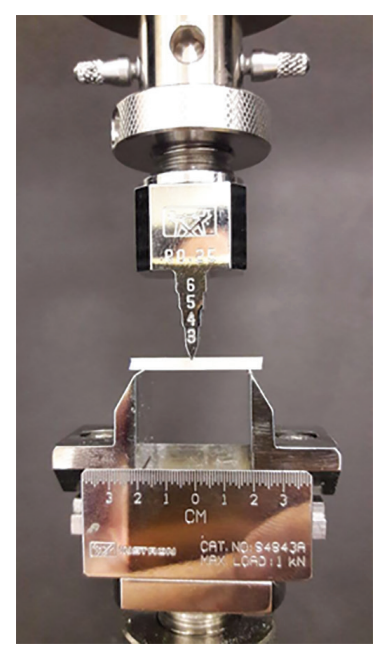

Fig. 2: Flexural strength testing assembly using three-point test

stored in an incubator (Memmert Edestahl, Rostfrei, West Germany) at $37^{\circ} \mathrm{C}$ and $100 \%$ relative humidity for 24 hours. Half of the samples in each material group (five specimens) were thermocycled for 5,000 cycles at 5 and $55^{\circ} \mathrm{C}$ (dwelling time, 30 seconds). All specimens were fixed in a holder and the test surface was perpendicular to the indenter tip with shape of right pyramid with a square base having the angle between opposite faces of $136^{\circ}$. Surface microhardness of the samples was determined using (Innovatest, Micro Vickers tester, Micro-Met II, BUEHLER, IL, USA) a Vickers diamond indenter with a $50 \mathrm{gf}$ load applied for a duration of 15 seconds. The indentations were measured by a built-in graduated microscope with $\times 40$ objective lens. Five indentations were made for each tested sample and the mean was identified.

\section{Statistical Analysis}

Univariate two-way ANOVA, one-way ANOVA, and Tukey post hoc tests (version 20.0, IBM, New York, USA) $(\alpha=0.05)$ were performed to analyze significant differences in FS, DTS, and VHN (dependent variable) between different materials and aging groups (independent variables). The independent $t$-test was used to detect differences $(\alpha=0.05)$ in FS, DTS, and VHN between groups for each material. All data were subjected to Levene's test of homogeneity of variance $(\alpha=0.05)$ following the assumption of equal variances.

\section{RESULTS}

Table 2 presents FS of the bulk-fill materials and the percent decrease after thermocycling. The results indicate that N-Ceram $(140.56 \pm 1.60)$, ACTIVA $(138.24 \pm 4.69)$, and SDR $(138.50 \pm 1.68)$ demonstrated the highest and comparable ( $p>0.05)$ FS, whereas Ketac $(12.68 \pm 1.49)$ had the lowest FS prior to the thermocycling. Thermocycling
Ten cylindrical $(4 \times 6 \mathrm{~mm})$ specimens for each material were fabricated according to the technique explained in earlier sections. The specimens were trimmed using a 600-grit $\mathrm{SiC}$ abrasive and assessed using a digital caliper (Mitutoyo Corp., Tokyo, Japan). The specimens were 
Table 2: Flexural strength before and after thermocycling

\begin{tabular}{|c|c|c|c|c|}
\hline \multirow[b]{2}{*}{ Material } & \multicolumn{2}{|c|}{ Mean MPa (SD) } & \multirow[b]{2}{*}{$p$-value } & \multirow{2}{*}{$\begin{array}{l}\text { Percent } \\
\text { decrease }\end{array}$} \\
\hline & Before & After & & \\
\hline ACTIVA & $138.24(4.69)^{a}$ & $109.97(1.21)^{a * *}$ & $<0.001$ & 20.45 \\
\hline Fuji & $37.49(1.30)^{b}$ & $35.82(0.82)^{\mathrm{b} *}$ & 0.041 & 4.45 \\
\hline Ketac & $12.68(1.49)^{c}$ & $07.24(0.85)^{\mathrm{C**}}$ & $<0.001$ & 42.90 \\
\hline $\mathrm{N}$-Ceram & $140.56(1.60)^{a}$ & $94.72(1.82)^{d * *}$ & $<0.001$ & 32.61 \\
\hline SDR & $138.50(1.68)^{a}$ & $130.02(0.89)^{\mathrm{e} * *}$ & $<0.001$ & 6.12 \\
\hline
\end{tabular}

Same superscript lowercase letters demonstrate no significant differences between materials (columns), while *denotes a significant difference and ${ }^{* *}$ denote a highly significant difference between tested groups (rows)

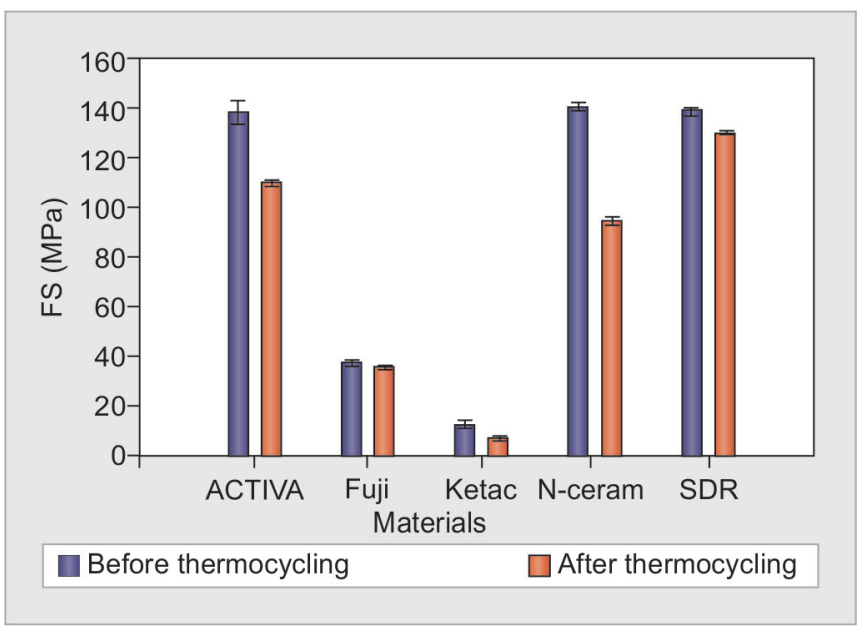

Graph 1: Presentation of FS among compared restorative materials before and after thermocycling using a bar graph

significantly reduced tensile strength $(\mathrm{p}<0.01)$ among all study groups. It is worth mentioning that SDR (130.02 \pm 0.89 ) had the highest FS post-thermocycling and the decrease in FS was also lower (6\%). Fuji had the lowest percent decrease $(4.45 \%)$ in FS post-thermocycling; in addition, it also showed the lowest FS ( $35.82 \pm 0.82)$ except for Ketac material (Table 2 and Graph 1).

The results of DTS are shown in Table 3. The findings demonstrate that SDR $(141.28 \pm 0.94)$ had the highest value, followed by N-Ceram (136.61 \pm 1.56$)$ and ACTIVA $(129.05 \pm 1.78)$. It was revealed that SDR $(139.08 \pm 1.36)$ maintained the highest value of DTS post-thermocycling. Furthermore, the percent decrease in DTS in SDR was also marginal. Ketac showed the lowest DTS before (40.22 \pm 2.17) and after (37.22 \pm 0.77$)$ thermocycling among all study groups. There was significant difference in the tensile strength values between all groups $(p<0.05)$. Thermocycling showed significant reduction in FS of specimens in all study groups $(\mathrm{p}<0.05)($ Graph 2$)$.

The VHN values among the study groups are presented in Table 4. The VHN was significantly different among all study groups $(\mathrm{p}<0.05)$. It was observed that ACTIVA (before, $22.67 \pm 0.35$; after $22.59 \pm 0.77$ ) had the lowest VHN value, whereas Ketac (before, $98.89 \pm$ 0.44 ; after, $80.35 \pm 1.93$ ) had the highest value of VHN
Table 3: DTS before and after thermocycling

\begin{tabular}{lllrl}
\hline & \multicolumn{2}{c}{ Mean MPa (SD) } & & \multicolumn{2}{c}{$\begin{array}{l}\text { Percent } \\
\text { Material }\end{array}$} & Before & After & p-value & decrease \\
\hline ACTIVA & $129.05(1.78)^{\mathrm{a}}$ & $103.94(1.29)^{\mathrm{a} *}$ & $<0.001$ & 19.46 \\
Fuji & $106.74(1.32)^{\mathrm{b}}$ & $74.43(1.31)^{\mathrm{b} * *}$ & $<0.001$ & 30.27 \\
Ketac & $40.22(2.17)^{\mathrm{c}}$ & $37.22(0.77)^{\mathrm{c} *}$ & 0.020 & 7.46 \\
N-Ceram & $136.61(1.56)^{\mathrm{d}}$ & $120.33(2.35)^{\mathrm{d} * *}$ & $<0.001$ & 11.92 \\
SDR & $141.28(0.94)^{\mathrm{e}}$ & $139.08(1.36)^{\mathrm{e} *}$ & 0.018 & 1.56 \\
\hline
\end{tabular}

Same superscript lowercase letters demonstrate no significant differences between materials (columns), while *denotes a significant difference and ${ }^{* *}$ denote a highly significant difference between tested groups (rows)

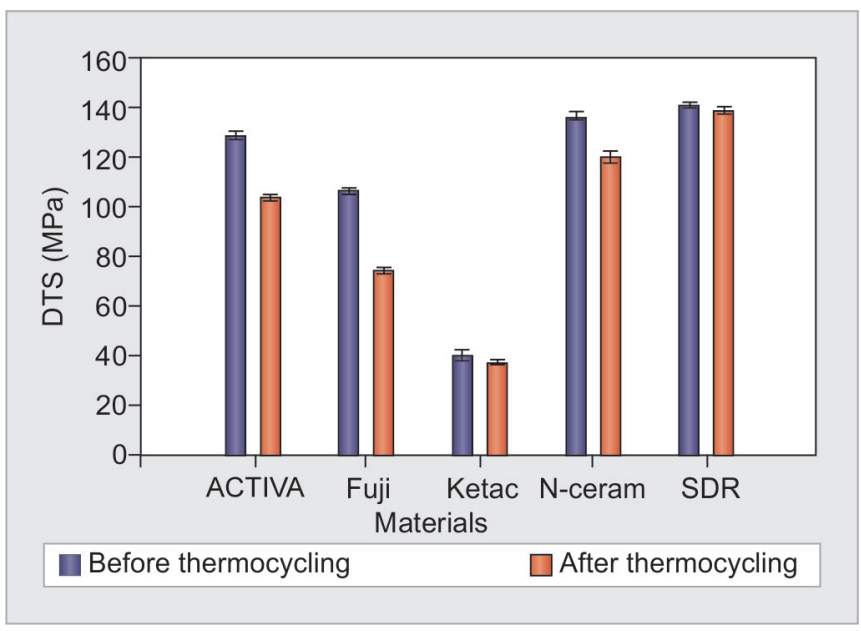

Graph 2: Presentation of DTS among compared restorative materials before and after thermocycling using a bar graph

before and after thermocycling. It is worth noting that thermocycling had no considerable influence on the VHN of ACTIVA $(p=0.83)$ and N-Ceram $(p=0.20)$. Thermocycling significantly reduced $(P<0.01)$ VHN for Fuji, Ketac, and SDR materials (Table 4 and Graph 3).

\section{DISCUSSION}

The present study was based on the hypothesis that the mechanical properties (FS, DTS, and microhardness [VHN]) tested are comparable among bioactive, $\mathrm{RBC}$, and GIC bulk-fill materials. The assessed properties, which included FS, DTS, and microhardness (VHN) of Bioactive bulk-fill (ACTIVA), were significantly better than bulk-fill GIC. Bioactive restorative material (ACTIVA Bulk Fill) showed comparable FS and DTS with conventional RBC. Therefore, the study hypothesis was rejected.

The present study simulated the oral temperature changes by undertaking thermocycling for half of the samples included in each study group. Only five samples were included in groups with and without thermocycling. A power analysis at $80 \%$ power was performed to identify samples size (five samples) from means and standard deviations (SDs) from previous studies. ${ }^{16}$ The present study compared the mechanical properties of RBCs, GICs, and bioactive RMGIC, as these are commonly used 


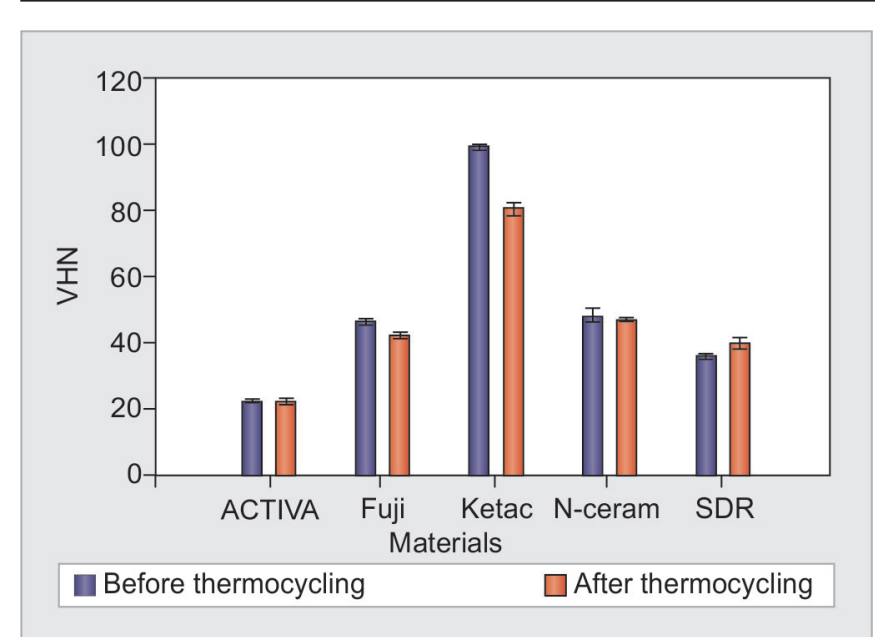

Graph 3: Presentation of surface microhardness among compared restorative materials before and after thermocycling using a bar graph

Table 4: The VHN before and after thermocycling

\begin{tabular}{lllrl}
\hline & \multicolumn{2}{c}{ Mean (SD) } & & Percent \\
\cline { 2 - 3 } Material & Before & \multicolumn{1}{l}{ After } & -value & decrease \\
\hline ACTIVA & $22.67(0.35)^{\mathrm{a}}$ & $22.59(0.77)^{\mathrm{a}}$ & 0.838 & 0.35 \\
Fuji & $46.43(0.64)^{\mathrm{b}}$ & $42.40(0.62)^{\mathrm{b} * *}$ & $<0.001$ & 9.50 \\
Ketac & $98.89(0.44)^{\mathrm{c}}$ & $80.35(1.93)^{\mathrm{c} * *}$ & $<0.001$ & 23.07 \\
N-Ceram & $48.49(2.04)^{\mathrm{d}}$ & $47.22(0.22)^{\mathrm{d}}$ & 0.202 & 2.69 \\
SDR & $36.14(0.60)^{\mathrm{e}}$ & $30.05(1.55)^{\mathrm{e} * *}$ & $<0.001$ & 20.27
\end{tabular}

Same superscript lowercase letters demonstrate no significant differences between materials (columns), while *denotes a significant difference and ${ }^{* *}$ denote a highly significant difference between tested groups (rows)

materials in dental-restorative procedures. The fracturerelated properties of materials are determined by FS testing and are critical if the material is used for Class I, II, or IV cavities. ${ }^{17}$ The FS of materials under transverse bending has been suggested as a way of measuring their brittleness. In addition, tensile stress induced by bending should be highest at the outermost layer of the test specimens as failure begins at the surface. Therefore, the surface characteristics of restorative materials may affect the FS. ${ }^{16}$

For screening of resin-based materials, $\mathrm{FS}$ is one of the key mechanical properties selected by the International Organization for Standardization (ISO). ${ }^{18}$ The ISO has set $80 \mathrm{MPa}$ as the minimum FS (benchmark) for polymerbased filling and restorative materials as suitable and acceptable for restorations involving outer occlusal surfaces. ${ }^{18}$ The findings for the FS revealed that N-Ceram, ACTIVA, and SDR demonstrated the highest and comparable FS, whereas Ketac and Fuji showed lower FS. By contrast, in a study by Pameijer et al, ${ }^{19}$ FS of RMGIC was found greater than conventional composite resin materials. The reason for higher FS in their study could be derived from the fact that resin composite was of the flowable type with low filler-to-resin ratio. In addition, bioactive RMGIC showed FS to be superior to conventional
GIC materials (Fuji, Ketac) as tested in the present study. ${ }^{19}$ The FS values for N-Ceram, ACTIVA, and SDR were higher than the benchmark value of ISO $(80 \mathrm{MPa})$, which is satisfactory for outer occlusal surface restorations as per ISO standard. The difference in the FS of tested materials is attributed to the difference in their composition, type of resin, inorganic filler, and size and content of filler. Generally, bisphenol-A glycidyl-methacrylate (Bis-GMA) is used as a matrix resin, synthesized from an epoxy resin and methyl methacrylate; thus, it is rigid and so presents high viscosity. In addition, urethane dimethacrylate (UDMA) is one of the examples carrying higher molecular weight (MW $=470 \mathrm{~g} / \mathrm{mol}$ ) and low viscosity with high flexibility resulting in higher FS, elastic modulus, and hardness. ${ }^{20}$ Moreover, Bis-EMA (ethoxylated version of Bis-GMA), a high molecular weight (MW $=540 \mathrm{~g} / \mathrm{mol}$ ) and lower viscosity monomer, exhibits higher DC and better mechanical properties. ${ }^{21}$ Referring to Table 1, the composition of N-Ceram is based on Bis-EMA, and SDR based on UDMA copolymer system, while ACTIVA is a blend of diurethane (UDMA) with other methacrylates. The high FS of these materials could be attributed to the presence of these higher molecular weight monomers. This argument can be supported by the previous studies, which showed that replacement of Bis-GMA or triethylene glycol dimethacrylate (TEGDMA) with UDMA can enhance both the FS and DTS. ${ }^{22}$ Furthermore, the DC is known to influence mechanical properties. ${ }^{22}$ In contrast to Bis-GMA, UDMA has shown stronger hydrogen bonding potential, shorter cross-links, and less cyclization resulting in higher FS and elastic modulus. ${ }^{23}$

The material stability and the filler/matrix interaction were assessed by thermocycling. Thermocycling results in surface stresses and microcracks due to high thermal gradients near the surface and filler/polymer interface respectively. ${ }^{24}$ In the present study, although $\mathrm{N}$-Ceram and ACTIVA (Bioactive) showed high FS and DTS initially, thermocycling resulted in a significant decrease in these properties [FS (32.61, 20.45\% respectively); DTS $(11.92,19.46 \%$ respectively)]. Conversely, SDR did not show any significant decrease both in the FS and DTS $(6.12,1.56 \%)$ after thermocycling. This may be attributed to the strong filler-matrix interaction of this material. Ketac demonstrated highest decrease $(42.90 \%)$ in FS postthermocycling, indicating its susceptibility to thermal aging. On the contrary, although Fuji showed lower FS initially, no significant decrease was observed and the decrease in FS post-thermocycling was negligible ( $4.45 \%$ ). The DTS test may reveal different values based on the differences between the polymeric matrix, size of fillers, and bond between fillers and matrix. ${ }^{22}$ The matrix containing Bis-GMA is an aromatic ester of a dimethacrylate, fabricated from an epoxy resin and methyl methacrylate. 
This makes it rigid with high viscosity. Therefore, different materials in the present study displayed variable DTS. Interestingly, this is the first study investigating DTS and surface microhardness of bioactive (ACTIVA-Bio Active) restorative materials in comparison withconventional resin composite and GIC materials.

Regarding microhardness, Ketac exhibited highest microhardness as well as significant decrease (23\%) in microhardness after thermocycling, which affirms it as the unstable material. Although N-Ceram and ACTIVA were found to have lower values of hardness before thermocycling, however, no significant difference was found before and after thermocycling. Their percent decrease in microhardness post-thermocycling was noticeably lower with values of $2.69 \%$ (N-Ceram) and $0.35 \%$ (ACTIVA) respectively. Thus, the influence of thermocycling on ACTIVA was insignificant; thereby, it may be regarded as the most stable material in terms of hardness subsequent to the thermocycling. However, no previous studies have assessed the effect of thermocycling on the FS, DTS, and VHN of bioactive (ACTIVA) materials. In addition, SDR had considerably lower value of microhardness before thermocycling, together with the higher percent decrease post-thermocycling, which may be attributed to the presence of organic matrix, based on UDMA. This finding is in agreement with Sideridou et $\mathrm{al}^{25}$ and Ho et $a{ }^{26}{ }^{26}$ who found that microhardness and stability values of UDMA-based material decreased significantly after thermocycling. Therefore, larger microhardness value of $\mathrm{N}$-Ceram may also endow with the inclusion of Bis-GMA.

\section{CONCLUSION}

Bioactive restorative material (ACTIVA Bulk Fill) showed comparable FS and DTS with conventional RBC in an in vitro environment. The bioactive material (ACTIVA Bulk Fill) showed properties (DTS and FS) superior to GIC (Fuji and Ketac). Durability of ACTIVA Bulk Fill was comparable or superior to conventional restorative materials.

\section{REFERENCES}

1. Pallesen U, van Dijken JW. A randomized controlled 30 years follow up of three conventional resin composites in class II restorations. Dent Mater 2015 Oct;31(10):1232-1244.

2. Leprince JG, Leveque P, Nysten B, Gallez B, Devaux J, Leloup G. New insight into the "depth of cure" of dimethacrylatebased dental composites. Dent Mater 2012 May;28(5):512-520.

3. Gajewski VE, Pfeifer CS, Fróes-Salgado NR, Boaro LC, Braga RR. Monomers used in resin composites: degree of conversion, mechanical properties and water sorption/solubility. Braz Dent J 2012 Sep-Oct;23(5):508-514.

4. Chesterman J, Jowett A, Gallacher A, Nixon P. Bulk-fill resinbased composite restorative materials: a review. Br Dent J 2017 Mar;222(5):337-344.
5. Li X, Pongprueksa P, Van Meerbeek B, De Munck J. Curing profile of bulk-fill resin-based composites. J Dent 2015 Jun;43(6):664-672.

6. Pereira PN, Inokoshi S, Yamada T, Tagami J. Micro-hardness of in vitro caries inhibition zone adjacent to conventional and resin-modified glass-ionomer cements. Dent Mater 1998 Jun;14(3):179-185.

7. Didem A, Gözde Y, Nurhan Ö. Comparative mechanical properties of bulk-fill resins. Open J Compos Mater 2014 Apr;4(2):117-121.

8. Palin WM, Fleming GJ, Burke FJ, Marquis PM, Randall RC. The reliability in flexural strength testing of a novel dental composite. J Dent 2003 Nov;31(8):549-557.

9. Jefferies S. Bioactive and biomimetic restorative materials: a comprehensive review. Part II. J Esthet Restor Dent 2014 Jan-Feb;26(1):27-39.

10. Welch K, Cai Y, Engqvist H, Strømme M. Dental adhesives with bioactive and on-demand bactericidal properties. Dent Mater 2010 May;26(5):491-499.

11. Ho E, Marcolongo M. Effect of coupling agents on the local mechanical properties of bioactive dental composites by the nano-indentation technique. Dent Mater 2005 Jul;21(7):656-664.

12. Khoroushi M, Keshani F. A review of glass-ionomers: from conventional glass-ionomer to bioactive glass-ionomer. Dent Res J (Isfahan) 2013 Jul-Aug;10(4):411-420.

13. Reyes-Carmona JF, Santos AS, Figueiredo $\mathrm{CP}$, Baggio $\mathrm{CH}$, Felippe MC, Felippe WT. Host-mineral trioxide aggregate inflammatory molecular signaling and biomineralization ability. J Endod 2010 Aug;36(8):1347-1353.

14. Goldberg M, Lacerda-Pinheiro S, Jegat N, Six N, Septier D, Priam F, Bonnefoix M, Tompkins K, Chardin H, Denbesten P, et al. The impact of bioactive molecules to stimulate tooth repair and regeneration as part of restorative dentistry. Dent Clin North Am 2006 Apr;50(2):277-298.

15. Dong Q, Chow LC, Wang T, Frukhtbeyn SA, Wang F, Yang M, Mitchell JW. A new bioactive polylactide-based composite with high mechanical strength. Colloids Surf A Physicochem Eng Asp 2014 Sep;457:256-262.

16. Kawano F, Ohguri T, Ichikawa T, Matsumoto N. Influence of thermal cycles in water on flexural strength of laboratoryprocessed composite resin. J Oral Rehabil 2001 Aug;28(8): 703-707.

17. Ersoy M, Civelek A, L'Hotelier E, Say EC, Soyman M. Physical properties of different composites. Dent Mater J 2004 Sep;23(3):278-283.

18. Standard, I. ISO 4049 Polymer Based Filling. Restorative and luting materials. Geneva: International Organization for Standardization; 2000. p. 1-27.

19. Pameijer $\mathrm{CH}$, Garcia-Godoy F, Morrow BR, Jefferies SR. Flexural strength and flexural fatigue properties of resinmodified glass ionomers. J Clin Dent 2015;26(1):23-27.

20. Floyd CJ, Dickens SH. Network structure of Bis-GMA-and UDMA-based resin systems. Dent Mater 2006 Dec;22(12): 1143-1149.

21. Ogliari FA, Ely C, Zanchi CH, Fortes CB, Samuel SM, Demarco FF, Petzhold CL, Piva E. Influence of chain extender length of aromatic dimethacrylates on polymer network development. Dent Mater 2008 Feb;24(2):165-171.

22. Asmussen E, Peutzfeldt A. Influence of UEDMA, BisGMA and TEGDMA on selected mechanical properties of experimental resin composites. Dent Mater 1998 Jan;14(1):51-56. 
23. Pfeifer CS, Shelton ZR, Braga RR, Windmoller D, Machado JC, Stansbury JW. Characterization of dimethacrylate polymeric networks: a study of the crosslinked structure formed by monomers used in dental composites. Eur Polym J 2011 Feb;47(2):162-170.

24. Chadwick RG, McCabe JF, Walls AW, Storer R. The effect of storage media upon the surface micro-hardness and abrasion resistance of three composites. Dent Mater 1990 Apr;6(2):123-128.
25. Sideridou ID, Karabela MM, Bikiaris DN. Aging studies of light cured dimethacrylate-based dental resins and a resin composite in water or ethanol/water. Dent Mater 2007 Sep;23(9):1142-1149.

26. Ho CT, Vijayaraghavan T, Lee SY, Tsai A, Huang HM, Pan LC. Flexural behaviour of post-cured composites at oral-simulating temperatures. J Oral Rehab 2001 Jul;28(7): 658-667. 